\title{
Caracterizando a evolução da eletrificação rural brasileira'
}

\author{
ALEXANDRE COSME JOSÉ JERONYMO \\ SINCLAIR MALLET- GUY GUERRA \\ Universidade Federal do $A B C$
}

\section{Resumo}

Ao longo do século XX, foram implementados, no Brasil, programas de eletrificação rural públicos e privados. Esses Programas ampliaram o acesso à prestação do serviço, mas não conseguiram atender ao conjunto das famílias residentes nos bairros rurais e interessadas no fornecimento. Este artigo recupera a legislação para a eletrificação rural brasileira, destaca a confusão institucional provocada pelos diferentes programas implementados simultaneamente e identifica a compra da infraestrutura como um dos obstáculos para estratos da população rural acessar o serviço. Foram selecionados os programas PROLUZ (I e II), Luz da Terra e Luz no Campo, referências para a eletrificação rural de baixo custo e para o atendimento das famílias interessadas. $O$ artigo avança até a universalização do acesso e uso da energia elétrica e o Programa Luz Para Todos. Os procedimentos para o desenvolvimento do artigo foram a pesquisa bibliográfica, a legislação e a identificação de elementos que potencializam e limitam as experiências com eletrificação rural. Os principais resultados mostram que: a compra da infraestrutura para eletrificação rural exclui famílias interessadas neste serviço; o apoio político determina o acesso à energia elétrica para os bairros rurais; a universalização e o Programa Luz Para Todos desenvolveram aprendizados com programas de eletrificação rural anteriores; as novas dinâmicas rurais promovidas pelo acesso à eletricidade requerem análises e estudos prospectivos.

Palavras-Chave: Programas de eletrificação rural. Universalização do acesso. Ações multissetoriais. 


\title{
Characterizing the evolution of the brazilian rural electrification
}

\begin{abstract}
Troughout century XX public and private programs of rural electrification. These Programs had extended the access in the provision of the service, but did not attend the families residing in the rural districts and interested in the supply. This article recover the legislation for the brazilian rural electrification, highlights the institutional confusion caused by the different implemented programs simulaneously, Identifies the purchase of the infrastructure for provision of the service as an economic barriers for social stratum of the rural population access the supply. The programs PROLUZ (I and II), Luz da Terra and Luz no Campo had been selected, as references for rural electrification low-cost and for the provision of the service to interested families. The article advances to the universalization of access and use of electricity and the Programa Luz Para Todos. The procedure for the development of the article were bibliographic research, the use of legislation, and are presented elements of the potential and limits of experiences with rural electrification. The main results show that: The purchase of infrastructure for rural electrification excludes families interested in this service; the political support determines the access to electric energy for the rural districts; the universalization and PLPT have developed learning from previous rural electrification programs; the new rural dynamics promoted by access to electricity require analysis and prospective studies.

Keywords: Programs of rural electrification. Universal access. Multisector action.
\end{abstract}

Caracterizando la evolución de la electrificación rural brasilera

\section{Resumem}

Durante el siglo XX, en Brasil fueron implementados programas de electrificación rural, públicos y privados. Esos Programas ampliaron el acceso a la prestación del servicio pero no pudieron atender al conjunto de las familias residentes en los barrios rurales $y$ e interesadas en el suministro. Este artículo recupera la legislación concermiente a la electrificación rural brasilera, destaca la confusión institucional provocada por los programas implementados simultaneamente, y apunta la compra de la infraestructura como uno de los obstáculos para estratos de la población rural acceder al servicio. Fueron seleccionados los programas PROLUZ (I e II), Luz da Terra e Luz no Campo, referencias de la electrificación rural de bajo costo para cubrir la demanda por electrificacción de las familias interesadas. El artículo avanza hasta la implementacción de la universalización del acceso y uso de energía electrica con el Programa Luz para todos. Los procedimientos para el desarrollo del artículo fueron la investigación bibliográfica, el uso de la legislación y la identificación de los elementos que potencian y limitan las experiencias con electrificación rural. Los principales resultados muestran que: la compra de la infraestructura para electrificación rural excluye a las familias interesadas en este servicio; el apoyo político determina el acceso a la energía eléctrica para los barrios rurales; la universalización y el PLPT desarrollaron aprendizajes con programas de electrificación rural anteriores; las nuevas dinámicas rurales alimentadas por el acceso a la electricidad requieren análisis y estudios prospectivos.

Palavras clave: Programas de electrificatión rural. Universalización del acceso. Acción multisector.

\section{Apresentação}

O fornecimento de energia elétrica para os bairros urbanos apresenta as menores complexidades e custos econômicos quando comparado com os bairros rurais. Essa limitação, no percurso histórico, em geral é associada à distância entre 
os principais centros consumidores de energia elétrica e as famílias residentes nos bairros rurais, ao elevado custo da extensão da rede de distribuição, à limitada renda familiar para comprar a infraestrutura para o fornecimento do serviço e à ideológica concepção de que essas famílias consumiam pouca eletricidade.

No conjunto desse processo, estão presentes as ações que podem contribuir ou obstruir a extensão da rede de distribuição de energia elétrica rural. Por um lado, estão as "figuras humanas de sensibilidade social que conseguiram impor as suas convicções pessoais à política tradicional” (CAMARGO, RIBEIRO, GUERRA, 2008, p. 22) e incentivaram com recursos econômicos próprios a expansão da eletrificação rural no País, e estão as "iniciativas isoladas e desarticuladas [...] dos órgãos de desenvolvimento dos governos estaduais e federais” (RIBEIRO, 1993). Por outro lado, e como processo que limitava a extensão da rede, estavam os procedimentos das empresas "Concessionárias de distribuição de energia elétrica que utilizavam cadastramentos excludentes, com alto custo por ligação, para reduzir a aquisição do serviço pela população rural mais pobre (STRAZZI, 2009, p. 21) e a lógica fria dos funcionários dessas empresas para justificar o não atendimento dos bairros rurais a partir do juízo de valor "eles não tem o que fazer com a eletricidade, não agregam valores", "não pagam o medidor", "são tão pobres que não nos interessam" (RIBEIRO, 1993). É um histórico que agrega um conjunto de procedimentos e metodologias fortemente excludentes para o proletariado rural.

Para a construção do artigo, será utilizada a técnica de pesquisa bibliográfica (teses, dissertações, artigos em periódicos) e a utilização de documentos públicos (leis e decretos). As contribuições e estratégias dos programas de eletrificação rural PROLUZ (I e II), Luz da Terra e Luz no Campo são identificados como aprendizagens para alcançar a universalização do acesso e uso da energia elétrica.

Este artigo recupera os princípios da eletrificação rural brasileira, constata a denominada confusão institucional provocada pela existência de diferentes programas de eletrificação implementados simultaneamente, e identifica que a compra da infraestrutura foi um dos elementos restritivos para o proletariado rural acessar o fornecimento de energia elétrica. $O$ artigo focaliza as contribuições do PROLUZ I e PROLUZ II, Luz da Terra e Luz no Campo, convenientes para nortear futuras extensões; avança até a Universalização do Acesso e Uso da Energia Elétrica e o Programa Nacional de Acesso e Uso da Energia Elétrica Luz Para Todos-PLPT, e defende que os conhecimentos e aprendizados produzidos pelo histórico dos programas de eletrificação rural brasileira contribuíram para reduzir a exclusão do fornecimento de energia elétrica a partir da Universalização e do PLPT.

$\mathrm{O}$ artigo traz esta e outras quatro seções. A segunda seção discorre sobre os princípios da eletrificação rural brasileira, e a confusão institucional, e a terceira, destaca as experiências dos programas de eletrificação rural PROLUZ I e PROLUZ II, Luz da Terra e Luz no Campo. A quarta seção apresenta a política de Universalização e o PLPT, e o paradigma do acesso gratuito para o fornecimento de energia elétrica rural, e aborda a multissetorialidade e as ações integradas orientadas para o atendimento às demandas sociais, culturais e econômicas das famílias atendidas. A quinta seção apresenta as considerações finais. 


\section{Princípios da eletrificação rural e a confusão institucional}

Considerando o desenvolvimento dos meios de produção paulista, não é surpresa constatar no interior deste Estado o princípio da eletrificação rural no País. Foi na cidade de Batatais, Estado de São Paulo (SP), em maio de 1923, que foi construída a primeira extensão de eletrificação rural brasileira. Ela está conectada "aos interesses da cafeicultura que prescindia deste e de outros investimentos, como a extensão da malha ferroviária e ampliação dos portos" (SOUZA, ANJOS, 2007, p. 42), e atendia "às demandas do imigrante europeu e a infraestrutura dos proprietários agrícolas paulistas (água potável, escolas, mecanização da atividade rural)" (RIBEIRO, 1993).

Embora os princípios da eletrificação rural brasileira estejam presentes no estado de São Paulo, a primeira cooperativa de eletrificação rural "foi fundada em 1941, em Quatro Irmãos, no Rio Grande do Sul” (RIBEIRO, 1993, p. 29). As cooperativas forneciam eletricidade a distritos e vilarejos, mediante 0 aproveitamento hidrelétrico ou de pequenos geradores acionados por motores (SOUZA, ANJOS, 2007, p. 43) e respondiam parcialmente pelo fornecimento de eletricidade no meio rural.

A eletrificação rural esteve presente nas agendas governamentais dos estados e da federação. O governo federal criou a lei $n^{\circ} 8 / 1948$ que instituiu 0 Serviço de Fomento à Eletrificação Rural com o fim de promover o emprego de eletricidade em zonas rurais (BRASIL, 1948) e para incentivar a formação das sociedades organizadas sem fins lucrativos ou o contrato com cooperativas rurais. Entretanto, enquanto ação de implementação governamental, "não houve qualquer resultado concreto a partir da aprovação dessa lei” (OLIVEIRA, 2001, p. 28) e o problema do fornecimento persistiu. A lei $n^{\circ} 41.019$ de 1957 responsabilizou a concessionária quanto ao fornecimento de energia elétrica regional (BRASIL, 1957), mas este outro instrumento legal não foi efetivo.

O governo do Estado de São Paulo criou o Serviço Especial de Eletrificação Rural-SEER, em 1959, e o Departamento de Águas e Energia Elétrica paulista apresentou o programa de eletrificação rural por intermédio de cooperativas, no ano de 1961 (OLIVEIRA, 2001, p. 28). Por sua vez, em Minas Gerais, a Companhia Energética de Minas Gerais-Cemig criou a Eletrificação Rural de Minas Gerais em 1962 e incentivou o fornecimento de energia elétrica rural organizado pelas cooperativas de eletrificação.

A eletrificação rural foi tema de debate em reuniões científicas e seminários nas décadas de 1950 e 1960. O Seminário Latino-americano para Eletrificação Rural, na cidade de Recife, em 1950, e o $1^{\circ}$ Simpósio Nacional de Eletrificação Rural, em 1967, são dois exemplos. Do Simpósio, em particular, houve a contribuição para organizar o marco regulatório da eletrificação rural, conforme o decreto $\mathrm{n}^{\circ}$ 62.655/1968 que regulamentou a "execução dos Serviços de Eletrificação Rural mediante autorização para o uso privado" (BRASIL, 1968a), e o decreto $\mathrm{n}^{\circ}$ $62.724 / 1968$ que estabeleceu "as normas gerais de tarifação para as empresas concessionárias do serviço público de energia elétrica e para identificar o consumidor rural" (BRASIL, 1968b).

Em 1959 o Departamento Nacional de Águas e Energia Elétrica-DNAEE trouxe a "polêmica referente à conceituação do que seria o consumidor de energia elétrica 
rural", e constituiu "comissão com competência de ampliar estes benefícios para outros beneficiários, provocando discussões referentes ao objeto da eletrificação rural” (SILVA, 1996, p. 9). Essas duas situações apontam para a necessidade que é a identificação da propriedade rural sem o serviço de energia elétrica e quais são as famílias responsáveis pelas propriedades.

O Estatuto da Terra, lei $n^{\circ} 4.504 / 1964$, priorizou os financiamentos públicos para os projetos de eletrificação rural organizados pelas cooperativas rurais (BRASIL, 1964). Entretanto, o "déficit energético rural persistiu devido à insuficiência de recursos para suprir as crescentes necessidades do meio rural, principalmente a partir da intensa mecanização ocorrida durante a revolução verde da década de 60" (OLIVERIA, 2001), e o estímulo aos "grandes produtores [...] representou crise na expansão do fornecimento de energia elétrica para pequenos e médios produtores, o que se refletiu no nível de penetração da eletricidade na zona rural" (MACINTYRE, 1996 apud OLIVEIRA, 2001). Com isso a expansão da eletrificação rural ficou comprometida, especialmente pelo baixo índice de rentabilidade do negócio (SOUZA, ANJOS, 2007), mas também pela opção do Estado em concentrar as políticas públicas de desenvolvimento rural em espaços agrícolas portadores de infraestruturas (estradas, rede de distribuição de água e esgoto, telecomunicações, acesso à eletricidade), e para valorizar as infraestruturas preexistentes nesses espaços e contribuir para atrair outras.

O processo que transita desde as primeiras extensões da eletrificação rural até o decreto $n^{\circ} 62.724 / 1968$ traz avanços no marco regulatório e no conjunto dos agentes envolvidos. Os serviços de eletrificação rural, as cooperativas rurais, a legislação em vigor, e a contribuição científica representaram objetivos com a extensão do acesso ao serviço de energia elétrica até os bairros rurais. Porém, ainda que os objetivos estivessem bem intencionados, não atendiam integralmente os diferentes estratos sociais da população rural. O resultado comum foi a exclusão do acesso e a constituição do proletariado rural, o estrato social incapaz de comprar o fornecimento de energia elétrica rural.

\subsection{A Confusão institucional}

A falta de visão integrada para planejar a expansão da rede de distribuição de energia elétrica rural criou um confuso ambiente institucional. Até meados dos anos 1960 "não havia uma visão integrada do planejamento, nem intercâmbio de informações, pois a atuação das concessionárias se dava de forma isolada, dentro de sua meta negocial" (MERCEDES, RICO, POZZO, 2015, p. 17). Atuaram, nesse período, diferentes empresas (públicas e privadas) que desenharam e implementaram simultaneamente programas de eletrificação rural próprios. 0 conjunto dessas ações configura a confusão institucional.

Havia, pois, a política de eletrificação rural do Ministério de Minas e Energia [...]. Havia, também, a política de eletrificação rural do Ministério da Agricultura, (...) através do II PNER, aplicando recursos captados junto ao BID. Aquela das concessionárias. A política das Cooperativas. A eletrificação rural do Brasil tornou-se uma grande confusão institucional. Estabeleceu-se uma dualidade de competências e programas (RIBEIRO, 1993). 
Este período da história da eletrificação rural brasileira é identificada como confusão institucional pela ausência de organização do poder público para definir os agentes e os órgãos responsáveis para implementar programas de eletrificação rural nacional. Na confusão institucional, os poderes públicos e a iniciativa privada executavam as atividades que apresentavam fins semelhantes, mecanismos e métodos diversos, custos diferenciados e resultados oscilando entre a satisfação e a insatisfação.

A ausência de ações integradas entre os agentes envolvidos e a não existência do marco regulatório para definir orientações gerais corroboraram a formalização da denominada confusão institucional.

Durante a década de 1970, foi instituído o decreto $n^{\circ}$ 67.052/1.970, do Fundo de Eletrificação Rural-FUER, que movimentou os recursos financeiros para 0 primeiro programa de eletrificação rural nacional, e foi criado o Grupo Executivo de Eletrificação Rural-GEER para atuar com as cooperativas agrícolas e viabilizar o fornecimento de energia elétrica rural. A metade dos recursos do FUER foi emprestado pelo Banco Interamericano de Desenvolvimento-BID, e a composição restante contou com recursos da União (30\%) e das cooperativas de eletrificação rural (20\%), que eram objeto final do empréstimo (OLIVEIRA, 1998).

A Eletrobras criou o Departamento de Eletrificação Rural-DEER em 1976 para atuar com as concessionárias de energia elétrica, atender à demanda pelo consumo de eletricidade rural, e trabalhar conjuntamente com o GEER.

O governo brasileiro e o BID celebraram contrato para executar $01^{\circ}$ Plano Nacional de Eletrificação Rural de Cooperativas-PNER I, entre os anos 1970-76, que é "considerado o marco inicial da eletrificação rural nacional, embora atingisse apenas nove estados" (PAGLIARDI et al, 2003). Em 1977 foi instituído o PNER II, financiado parcialmente pelo BID, que atendeu 73.369 propriedades rurais (OLIVEIRA, 1998, em 18 estados e no Distrito Federal, e construiu 40.537 km de redes de distribuição de energia (PEREIRA, 2009).

O BID e o Banco Mundial investiram em programas de eletrificação rural de algumas concessionárias estaduais, com o destaque para o da Companhia Paranaense de Energia-Copel no Paraná, e o da CEMIG em Minas Gerais (RIBEIRO, 2008).

A tabela 1 recupera uma parcela dos programas de eletrificação rural realizados. As diferenças na organização, financiamento e conexões implicaram no resultado final de cada programa. 
Tabela 1. Programas de eletrificação rural entre as décadas de 1970, 1980, 1990.

\begin{tabular}{|c|c|c|c|c|}
\hline Período & Organização & Programa & Ligações & Financiamentos \\
\hline $1970-1976(4)$ & $\begin{array}{l}\text { Ministério da } \\
\text { Agricultura }\end{array}$ & I PNER & 28.056 & $\begin{array}{c}\text { 47,4\% BID } \\
\text { 34,5\% Min Agri } \\
\text { 18,1\% usuários } \\
\end{array}$ \\
\hline $\begin{array}{l}1976-1980 \\
\text { (4) }\end{array}$ & $\begin{array}{c}\text { Eletrobras, } \\
\text { Concessionárias }\end{array}$ & Eletrobras de ER & 117.100 & $\begin{array}{c}\text { 52,3\% Eletrobras } \\
\text { 47,7\%Concessionárias e } \\
\text { usuários }\end{array}$ \\
\hline $\begin{array}{l}1978-1981 \\
\text { (1) }\end{array}$ & $\begin{array}{l}\text { Ministério da } \\
\text { Agricultura }\end{array}$ & II PNER & 73.369 & $\begin{array}{c}\text { 50\% União } \\
\text { 33\% GEER } \\
\text { 17\% Cooperativas }\end{array}$ \\
\hline $1978(2)$ & Banco do Brasil & $\begin{array}{c}\text { Programa } \\
\text { Banco do Brasil }\end{array}$ & 1.083 & $100 \%$ interessados \\
\hline $1982(4)$ & $\begin{array}{l}\text { Ministério da } \\
\text { Agricultura }\end{array}$ & III PNER (1) & 4.402 & $-x-$ \\
\hline $1984-1989(2)$ & COPEL & Clic Rural I & 122.986 & $\begin{array}{l}50 \% \text { COPEL/BIRD } \\
50 \% \text { interessado }\end{array}$ \\
\hline 1986-1987(3) & $-x-$ & $\begin{array}{c}\text { Reassentamento } \\
\text { Itaparica }\end{array}$ & $-x-$ & U\$S1.100 (x1.000) \\
\hline $1987-1990(2)$ & COPEL & Clic Rural II & 39.954 & $\begin{array}{c}50 \% \text { COPEL } \\
50 \% \text { interessados }\end{array}$ \\
\hline 1989-1991(3) & Gov Bahia & Interluz & 36.000 & U\$S119.842 (x1.000) \\
\hline $1995-1998(2)$ & Gov Paraná & Lig Luz rural & 30.180 & $\begin{array}{c}(50 \%) \text { COPEL } \\
(50 \%) \text { Interessados }\end{array}$ \\
\hline 1991-1996(2) & Gov Paraná & Força Rural & 44.752 & $\begin{array}{c}(50 \%) \text { COPEL } \\
(50 \%) \text { Interessados }\end{array}$ \\
\hline 1990-1992(7) & $\begin{array}{c}\text { Gov } \\
\text { Rio Grande do Sul }\end{array}$ & PROLUZI & 4.000 & $\begin{array}{c}\text { Gov RS, } \\
\text { CEEE, BNDES }\end{array}$ \\
\hline 1993-1994(3) & Gov Bahia & CAR/PAPP & $x-x$ & US\$12 milhões \\
\hline 1994(6) & MME & PRODEEM & 8.912 & $\begin{array}{l}\text { BID, União Europeia, } \\
\text { USAID, PNUD, CEPEL, } \\
\text { CHESF, Eletronorte }\end{array}$ \\
\hline $1995-1996(1)$ & Gov Minas Gerais & Luz de Minas & 59.482 & $-x-$ \\
\hline $1995-1996(1)$ & Gov Pernambuco & Luz que Produz & 34.144 & $-x-$ \\
\hline $1995-1996(1)$ & Gov Pará & $-x-$ & 541 & $-x-$ \\
\hline $1995-1996(1)$ & Gov Amazonas & $-x-$ & 249 & $-x-$ \\
\hline 1995-1996(1) & Gov Tocantins & $-x-$ & 886 & $-x-$ \\
\hline 1995-1999(5) & $\begin{array}{c}\text { Gov } \\
\text { Rio Grande do Sul }\end{array}$ & PROLUZ II & 22.000 & $\begin{array}{l}\text { BNDES, } \\
\text { Banrisul }\end{array}$ \\
\hline $1996(5)$ & Gov São Paulo & Luz da Terra & 32.261 & $\begin{array}{c}\text { Gov SP, FEAP, } \\
\text { BNDES, Usuários }\end{array}$ \\
\hline
\end{tabular}

Fonte: (1) Oliveira, 1998, p. 90; (2) Massochin, (2006, p.60-61); (3) Correia et all (2002, p. 59); (4) Pagliardi et all (2003); (5) Marques (2005); (6) Tribunal de Contas da União (2003); (7) Ribeiro, Santos (1.994). BNDES, CEEE, CEPEL, CHESP, FEAP, CAR/PAPP (Programa Apoio ao Pequeno Produtor Rural do Nordeste), GOV (Governo), MME (Ministério de Minas e Energia), PNUD, PRODEEM, Projeto COOPERAR (Projeto de combate a pobreza rural do estado da Paraíba), USAID, Banrisul (Banco do Estado do Rio Grande do Sul).

Mesmo ocorrendo a denominada confusão institucional, os programas de eletrificação rural contribuíram para incrementar a quantidade de unidades domiciliares atendidas.

Indicadores do Instituto Brasileiro de Geografia e Estatística-IBGE mostram a evolução dos domicílios rurais atendidos com iluminação elétrica e a evolução dos domicílios rurais. 
Figura 1. Evolução dos domicílios rurais e evolução dos domicílios rurais atendidos com iluminação elétrica.

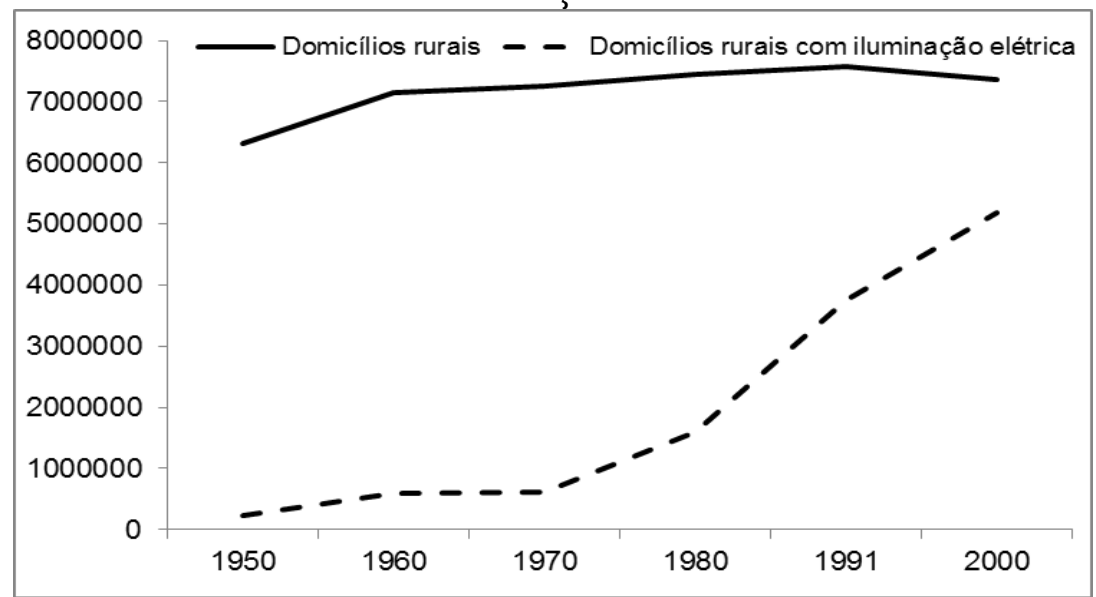

Fonte: IBGE, 2.000. (Figura elaborada pelos autores a partir dos dados do IBGE).

O avanço da eletrificação rural não pode ser dissociado da modernização agrícola, do latifúndio, da mecanização do trabalho no campo e do reduzido investimento na pequena produção agrícola. O conjunto deste histórico da agricultura brasileira contribuiu para restringir as atividades dos trabalhadores e trabalhadoras da agricultura e fortaleceu o êxodo rural.

Os programas de eletrificação rural cobravam pela instalação das infraestruturas (postes, cabos, fios, caixas de energia, transformadores), restringiam o acesso ao fornecimento do serviço e excluíam as famílias não portadoras do recurso econômico para a compra dos materiais e do serviço.

Essa particularidade produziu estratificação social entre aqueles que podiam e aqueles que não podiam pagar pelo serviço. O primeiro estrato é conformado pelos núcleos familiares em condições de comprar e pagar pelo acesso, e assim procediam. O segundo estrato representa o núcleo familiar que compra o acesso e não consegue cumprir com os pagamentos da aquisição, e, ao não quitar a dívida, o resultado é o acúmulo das parcelas não pagas, dívida ampliada, e o risco real da cobrança judicial. No segundo estrato, está a possibilidade que é o retorno à etapa que antecede o fornecimento, ou seja, a exclusão do serviço. O terceiro estrato é composto pelos núcleos familiares incapazes de demonstrar o interesse no acesso pelo motivo de não conseguirem reunir o volume de recursos econômicos necessários para a compra.

A crueza dessa estratificação, a partir das considerações econômicas, é um dos elementos que está no cerne da exclusão do fornecimento de energia elétrica, afetando, precisamente, as famílias rurais mais empobrecidas, as não portadoras de recursos econômicos para comprar o serviço.

O aporte de Ribeiro (1993) reconhece que é preciso vencer a barreira do custo da instalação porque a população mais pobre não terá como pagar. Para o proletariado rural, a compra da infraestrutura para o fornecimento de energia elétrica é uma barreira. Logo, a eletrificação rural, como política pública, necessita atender, satisfatoriamente, as famílias interessadas no serviço e não apenas as que podem pagar pelo serviço. 


\section{Programas de Eletrificação Rural}

Ao longo da década de 1980, os órgãos multilaterais restringiram investimentos para eletrificação rural. No Brasil, neste mesmo período, os recursos econômicos eram limitados. A literatura reconhece pouca transformação em termos de eletrificação rural no período (OLIVEIRA, 2001; PELEGRINI, 1998) e destaca a dependência dos escassos recursos das Concessionárias e crédito rural do Banco do Brasil (OLIVEIRA, 2001). Foi nesse período que o grupo de eletrificação rural da ELETROBRAS deixou de existir e os seus estudos foram interrompidos (RIBEIRO, 2008).

A contraposição desse quadro de limitados recursos para eletrificação rural está nos incentivos econômicos e políticos do Banco Nacional de Desenvolvimento Econômico e Social-BNDES. Nas décadas de 1980 e 1990 o BNDES contribuiu para implementar a política de eletrificação rural de baixo custo.

\subsection{Programa de Eletrificação Rural (PROLUZ I e PROLUZ II)}

No Município de Palmeiras das Missões, Rio Grande do Sul, foi implementado o projeto piloto do Programa de Eletrificação Rural de baixo custo-PROLUZ, e houve a participação econômica do BNDES.

No Rio Grande do Sul, foram implementados o PROLUZ I e o PROLUZ II. Esses dois programas são as primeiras experiências desse estado para ampliar o acesso ao fornecimento de eletricidade até os bairros rurais.

O PROLUZ caracteriza-se por colocar em escala experiências anteriores em eletrificação rural de baixo custo, as quais tem origem no trabalho do saudoso professor Ennio Amaral, da Escola Técnica Federal de Pelotas (ROSA, RIBEIRO, MELLO, 1993).

Relatam Rosa, Ribeiro, Mello (1993) que ocorreu no Município de Palmares do Sul, entre os anos de 1985 e 1988, autorizado pela Companhia Estadual de Energia Elétrica-CEEE, a implementação da experiência em eletrificação rural de baixo custo, como projeto piloto, e foi financiada pelo BNDES. Segundo os autores, essa experiência foi classificada pelo Banco como exitosa e há o reconhecimento dos avanços do projeto.

O BNDES apoiou a execução do modelo de eletrificação rural no Rio Grande do Sul, entretanto, ainda que houvesse o parecer positivo do Banco, o modelo proposto foi severamente restringido. A solução encontrada para prosseguir com o modelo foi política.

O conflito transbordou para a esfera política e o governador do Rio Grande do Sul chamou as partes - empreendedores de Palmares do Sul versus a engenharia de distribuição da Concessionária estadual - para um debate público, a sua frente, e com a participação do BNDES. Foi o Seminário sobre o custo do CAZ, em 1.988. Do alto da sua autoridade o governador Pedro Simon deu um mês de prazo para que elaborasse a norma técnica conclusiva. Indicativo de que as soluções de eletricidade são sempre políticas, a norma foi feita. Desta forma, implantou-se a norma técnica NTD 025m a qual foi utilizada nos programas PROLUZ I e PROLUZ II. (MARQUES, 2.005, p. 23).

As inovações do projeto piloto de Palmares do Sul estão circunscritas aos 
materiais e à metodologia do trabalho. A utilização de postes de madeira, pequenos transformadores, condutores de aço zincado, implantação de redes em regime de mutirão, um bom planejamento elétrico e sistema de financiamento possibilitou o rápido acesso à eletrificação rural de baixo custo para a população de baixa renda (ROSA, RIBEIRO, MELLO, 1993, p. 5). Nesse conjunto de procedimentos, está a real dimensão do consumo de energia elétrica rural, o que implica em reconhecer que as infraestruturas para este atendimento não necessitam da sofisticação urbana.

A disponibilização da força de trabalho comunitária, em regime de mutirão, para extensão da rede de distribuição, produz e sedimenta sentidos objetivos e subjetivos para as famílias beneficiadas. Objetivamente, o custo da infraestrutura para a prestação do serviço de energia elétrica é sensivelmente reduzido quando é utilizada a mão de obra comunitária e materiais com menor custo, e esta mesma metodologia produz sentimentos subjetivos de pertencimento e integração dos usuários e do Bairro Rural quando participam deste processo. Esse novo desenho para o fornecimento de energia elétrica rural reconhece as limitações econômicas dos usuários interessados no fornecimento do serviço.

Inicialmente, o PROLUZ I foi desenvolvido entre 1990 e 1992, e apoiado pelo BNDES, Banrisul, CEEE, governo do Rio Grande do Sul, e houve a participação da Escola Politécnica da Universidade de São Paulo-USP no acompanhamento e avaliação técnica do projeto.

Os recursos alocados pelo BNDES foram os de dotações com destinação social, fato que permitiu que as questões de garantia e risco tivessem um tratamento diferenciado do usualmente praticado, tendo o Banco assumido o risco sem exigência de garantias reais (RIBEIRO, SANTOS, 1994). O resultado é que o público alvo do programa - excluído das linhas de créditos rurais, desconfiados dos financiamentos bancários, renda baixa e limitadas garantidas para oferecer - foi beneficiado.

Este crédito foi concedido com dois anos de carência e quatro anos para reembolso com as seguintes condições: $2 / 3$ sob a forma de financiamento, com juros de $8 \%$ a.a. e correção monetária; e $1 / 3$ sob a forma de colaboração financeira não reembolsável (RIBEIRO, SANTOS, 1.994, p. 142).

O PROLUZ I "teve objetivo eletrificar 5.377 minifúndios em 44 municípios" (ROSA, RIBEIRO, MELLO, 1993), mas atendeu "4.000 famílias de produtores rurais de baixa renda em 47 municípios das regiões de Celeiro, Grande Santa Rosa e Alto Uruguai e apresentou inadimplência de 0,003\%, o que significa 15 tomadores em um universo de mais de 4.000 e um valor médio de US\$735,00 por propriedade conectada (RIBEIRO, SANTOS, 1994, p. 141, 142 e 150). É destacado que as reduzidas inadimplências e o reduzido valor da conexão podem ser identificados como resultados positivos para a experiência.

No trabalho de Carmo, consta a declaração do BNDES sobre a posição do Banco quando o assunto é a eletrificação rural social.

É possível fazer eletrificação rural a baixo custo. É possível incluir todas as classes sociais, mesmo as mais pobres nos programas de eletrificação rural. [...] Fica demonstrada a existência de um modelo de eletrificação rural capaz de atender o pobre rural, sem exclusão social (CARMO, 2.005, p. 42). 
A aceitação do PROLUZ I ressaltou a importância dos diferentes atores no processo de eletrificação rural e estimulou o BNDES a expandir a experiência para o País e as Concessionárias estaduais. Entretanto, ainda que demonstrado empiricamente, a experiência de eletrificação rural de baixo custo, mediante a utilização de materiais simples e com menor custo, sofreu questionamentos do mainstream das Concessionárias de energia elétrica e da engenharia tradicional. $O$ BNDES incentivou as Concessionárias do País para reproduzir a experiência do PROLUZ, mas houve a recusa para repetir a experiência "alegando além de motivos técnicos, que o pobre rural não tinha interesse ou que não tinha o que fazer com a energia elétrica, bem como que a Companhia não se interessava por esse tipo de consumidor" (MASSOCHIN, 2006, p. 35). Esse posicionamento pune o consumidor rural, ou porque é pobre ou porque é um consumidor supostamente incapaz de gerar rendimentos para a corporação empresarial. Posicionamento que confere a eletrificação rural como mercadoria, permitida unicamente enquanto relação de troca e para famílias portadoras do recurso econômico para a compra.

A concretização do PROLUZ I rompeu com os procedimentos ideologizados e com a postura conservadora da Concessionária. Segundo Ribeiro, Santos (1993, p. 150), a ação política do governo e a sua determinação quebrou, nesta ordem, o dilema da vontade política do estado. A política imposta pelo governo obrigou a Concessionária a priorizar o programa de eletrificação rural, e os dirigentes das Concessionárias souberam impor aos setores de engenharia corporativos o padrão técnico simplificado. Foram ações que contribuíram para integrar o proletariado rural às políticas públicas de desenvolvimento rural, e para modificar a relação entre os agentes públicos e privados quando o assunto é a eletrificação rural.

Foi desenhado o PROLUZ II e implementado entre os anos 1995 e 1999. O BNDES e o Banrisul participaram financeiramente. O PROLUZ II realizou 22.000 ligações elétricas no Rio Grande do Sul (MARQUES, 2005, p. 27). As experiências do PROLUZ I e PROLUZ II influenciaram a política de eletrificação rural no Estado de São Paulo (MARQUES, 2005, p. 28; PELEGRINI, 1998; STRAZZI, 2009, p. 29) e no território nacional, posteriormente.

\subsection{Programa Luz da Terra}

No Estado de São Paulo, foram desenvolvidos programas de eletrificação rural que repercutiram no cenário nacional. A Companhia Energética de São PauloCESP e a Companhia Paulista de Força e Luz-CPFL faziam a distribuição de eletricidade até os domicílios rurais paulistas. Ofereciam subsídios aos interessados, mas a empresa ficava com a maior parte do custo da conexão. Não havia o objetivo de universalização e o atendimento ocorria em determinadas regiões ou situações (STRAZZI, 2009). As determinadas regiões eram as regiões identificadas como aptas para receber a conexão. Portanto, a própria orientação dessas conexões é, por si só, excludente. Exclui as famílias, pessoas, e formas de subsistência em regiões determinadas.

Com o decreto $n^{\circ}$ 41.187/1996, foram instituídos o Programa de Eletrificação Rural Luz da Terra e a Comissão de Eletrificação Rural do Estado de São PauloCERESP. No decreto, consta a concessão de financiamentos à população rural, com 
recursos prioritários do BNDES e do Fundo de Expansão da Agropecuária e da Pesca-FEAP, tendo como agente financeiro a Nossa Caixa - Nosso Banco S.A, mas sem prejudicar a participação de outras fontes de recursos ou agentes financeiros, conforme o interesse dos beneficiários finais (SÃO PAULO, 1996).

A exitosa experiência do BNDES ao financiar os programas PROLUZ I e PROLUZ II orientou o modelo de eletrificação rural no Estado de São Paulo. Essa decisão alimentou novos pontos de vistas e paradigmas entre as Concessionárias estaduais e privadas de energia elétrica, e as cooperativas de eletrificação rural que atuavam em São Paulo (CARMO, 2005). O modelo de eletrificação rural proposto foi questionado tecnicamente pelo maistream do setor elétrico de São Paulo. A resolução para o problema foi política e não técnica.

Houve a intervenção governamental. O governador do Estado de São Paulo, Mário Covas, concedeu apoio e sustentação políticas ao projeto proposto pelo BNDES (CARMO, 2005) e esta ação, que é política, contribuiu definitivamente para suprimir os elementos críticos do Luz da Terra.

A ampliação da rede de distribuição do programa Luz da Terra utilizou técnicas e materiais orientados para reduzir o "custo por meio de concepções de projetos e métodos para fomentar a participação do poder público municipal e da população em geral" (BETIOL, 2005), e a utilização de "normas técnicas unificadas, adotando padrões simplificados e privilegiando, sempre que tecnicamente possível, o sistema monofilar com retorno por terra" (PAGLIARDI et al., 2003). A força de trabalho comunitária, os materiais tecnicamente eficientes (como os postes de madeira) e com reduzido custo compunham as estratégias para ampliar a rede. Por um lado, o objetivo em alcançar o menor custo e viabilizar o acesso para o proletariado rural era real e compunha o planejamento. Por outro lado, ainda que fosse um programa social, a compra do serviço era necessária, portanto, a meta do Luz da Terra nunca foi a universalização mas o atendimento da parcela do proletariado rural capaz de comprar o serviço de eletrificação.

O programa Luz da Terra envolvia as Secretarias de Energia, Agricultura e Abastecimento, Ciências, Tecnologia e Desenvolvimento Econômico, e de Economia e Planejamento. A concertação entre as diferentes secretarias e um conjunto diverso de políticas públicas anuncia que o acesso à eletrificação rural não é por si só para consumir eletricidade, mas também enquanto estratégia incentivadora da geração de renda, do acesso às políticas públicas, do desenvolvimento rural regional e para marcar a presença do estado.

O financiamento do programa Luz da Terra envolveu diferentes agentes e o próprio usuário.

$5 \%$ do valor total do projeto é de responsabilidade da concessionária de energia elétrica; $15 \%$ do valor total do projeto deve ser pago diretamente pelo interessado, em dinheiro ou através de serviços; $80 \%$ do valor total do projeto é financiado com recursos do BNDES aos próprios interessados, com juros de TJLP (taxa de juros a longo prazo) $+3,5 \%$ ao ano, com uma carência de seis meses a um ano e prazo de pagamento de até 72 meses. (RIBEIRO et al, 2003).

A intenção do Luz da Terra previa ampliar a rede de distribuição de energia elétrica para 150.000 residências (STRAZZI, 2009) e, ao final, ocorreram 32.261 conexões residenciais, portanto, um quantitativo bastante inferior ao planejamento inicial. 
Ainda que houvesse o planejamento orientado para a eletrificação rural de baixo custo, a política de comercialização da infraestrutura para a prestação do serviço restringiu o atendimento integral, o acesso universal e a manutenção da exclusão para parcela das famílias interessadas. Por outro lado, quando o Estado dilui os preciosismos e os modelos de eletrificação rural distantes da realidade rural, está em processo a aproximação com as dinâmicas e cotidianidades rurais e a ruptura com as técnicas que restringem o acesso ao fornecimento de energia elétrica.

Além disso, a presença do Estado para subtrair as questões técnicas rompeu com a eletrificação rural pautada em preciosismos e modelos de eletrificação rural distantes das realidades rurais.

\subsection{Programa Luz no Campo}

O ano 1999 marcou o reinicio, por parte do governo federal, do desenvolvimento de programas de eletrificação rural nacional. O retorno ocorreu com o Decreto Presidencial de 2/12/1999, que instituiu o Programa Nacional de Eletrificação Rural Luz no Campo para a expansão da rede de distribuição de energia elétrica no meio rural.

A execução do Luz no Campo utilizou como fundamento os conceitos de engenharia de baixo custo, "absorveu as inovações tecnológicas e sociais desenvolvidas no programa Luz da Terra" (STRAZZI, 2009, p. 39), logo, trouxe referências do PROLUZ. Os marcos do Luz no Campo foram orientados para "atender com o suprimento energia elétrica o meio rural, incentivar 0 desenvolvimento socioeconômico dessa área, contribuir para a permanência do homem no campo" (ELETROBRAS, 2009 apud STRAZZI, 2009, p. 38) elementos que evidenciam intenções com a fixação rural e a retenção do êxodo rural.

O recurso para a implementação do Programa Luz no Campo é o fundo setorial Reserva Global de Reversão (RGR), gerido pela ELETROBRAS. A RGR respondia por $75 \%$ dos projetos de eletrificação, e a diferença para completar 0 financiamento "ficava a cargo do poder público municipal, estadual, consumidores e empresas concessionárias e cooperativas de eletrificação rural responsáveis pelos projetos" (PEREIRA, 2009, p. 77).

As condições financeiras do Programa Luz no Campo podem ser resumidas desta forma:

\footnotetext{
valor máximo de até $75 \%$ do custo total da proposta, com um custo referencial de $\mathrm{R} \$ 3.200,00$ por ligação (US\$2.666,67 preços de 31/12/1998). Prazo de aplicação de até 24 meses e carência de até 24 meses. Juros de $5 \%$ a.a calculados sobre o saldo devedor corrigido, e taxa de administração de $1 \%$ a.a. (PEREIRA, 2009, p. 77).
}

O Luz no Campo, à época, foi classificado como o maior programa de eletrificação rural já desenvolvido no país (PEREIRA, 2009; SOUZA, ANJOS, 2007). A meta inicial foi a ampliação da rede para 1 milhão de propriedades e domicílios rurais em todo o território nacional, com investimento da ordem de R\$2,7 bilhões até o final de 2002, dos quais cerca de $\mathrm{R} \$ 1,8$ bilhão financiados pela ELETROBRAS via RGR, para beneficiar mais de 5 milhões de brasileiros até o final de 2002 (ELETROBRAS, 2002). A intenção da ELETROBRAS não foi integralmente cumprida. Ao final, o Luz 
no Campo atendeu a cerca de 3 milhões de pessoas e ampliou a rede para 0 equivalente a 680 mil domicílios em todo o Pais, e utilizou o investimento aproximado de $\mathrm{R} \$ 2,3$ bilhões no período compreendido entre os anos 2000 e 2004 (STRAZZI, 2009). A expectativa inicial, considerando o resultado final do programa, não foi alcançada.

O Luz da Terra e o Luz no Campo focavam "conceitos de engenharia de baixo custo por meio da utilização de padrões técnicos simplificados, o que tornava o custo da ligação elétrica mais acessível ao morador rural de baixo poder aquisitivo" (STRAZZI, 2009, p. 45). Os dois Programas, ao estabelecerem correspondência com os conceitos de engenharia de baixo custo, corroboraram o fortalecimento da denominada função social da eletrificação rural.

Ainda que houvesse a orientação para a redução do custo da instalação, o Programa Luz no Campo não era gratuito, a infraestrutura para o acesso do serviço de energia elétrica rural era comprada. Essa condição manteve longe do acesso as famílias que não conseguiam reunir a quantidade de dinheiro necessária para comprar as infraestruturas para instalação e o serviço.

\section{Programa Luz Para Todos}

A implementação dos programas de eletrificação rural até a finalização do Programa Luz no Campo atendeu parcialmente ao montante de famílias interessadas no acesso à energia elétrica. A restrição no atendimento, por diferentes motivos - pela distância dos principais centros consumidores de eletricidade, o elevado custo econômico das redes de distribuição, a ideológica concepção do reduzido consumo de energia elétrica no meio rural -, contribuiu para estruturar o deficit na prestação deste serviço.

A formulação do PLPT não contou com a pressão dos futuros beneficiários. No estudo do Instituto Interamericano de Cooperação para Agricultura-IICA está relatada a não verificação, no momento da formulação do PLPT, de a pressão por parte dos beneficiários pela universalização (IICA, 2011). Durante a formulação os principais interessados eram o poder público e as Concessionárias e Distribuidoras de energia elétrica. $E$ isso devido ao interesse desses agentes econômicos em utilizar recursos públicos enquanto estratégia para responder à crise do setor de energia elétrica, ocorrida no ano 2001.

A constatação de Ribeiro (2008) é que, no ano 2003, o Congresso Nacional foi chamado para discutir a recomposição do setor e resolver situações excepcionais de quebra de contrato de concessão por ocasião daquela crise de oferta de energia [no ano 2001], e no rastro dos ajustes foi originado o Acordo Geral (entre o setor elétrico e o governo federal) para recompor o ambiente do mercado de energia, e as concessionárias concordaram em aceitar a Universalização do Atendimento. A universalização foi identificada como um mecanismo para revitalizar a Indústria Brasileira de Energia Elétrica, abalada pela crise no fornecimento de eletricidade no ano de 2001.

Ao associar a universalização como resposta à crise, fica constituída que a demanda econômica da indústria de eletricidade determinou a demanda social pelo acesso à energia elétrica. A histórica exclusão familiar desse acesso não correspondia e não respondia à valorização do capital da indústria de energia 
elétrica, e o desenho da política de universalização respondeu aos interesses políticos e macroeconômicos envolvidos pela crise do ano 2001 (JERONYMO, 2012). As crises no abastecimento de energia elétrica, a recomposição do setor e o Acordo Geral são contribuições para compreender e ausência das famílias beneficiadas pelo PLPT no ato que é a formulação do Programa em si.

O que realmente consta na formulação do PLPT é o deficit de ligação rural representado pelos 2.034.794 de unidades domiciliares, conforme informação do IBGE.

Figura 2. Estimativas de deficit de ligações rurais por estado da federação no início do Programa Luz Para Todos

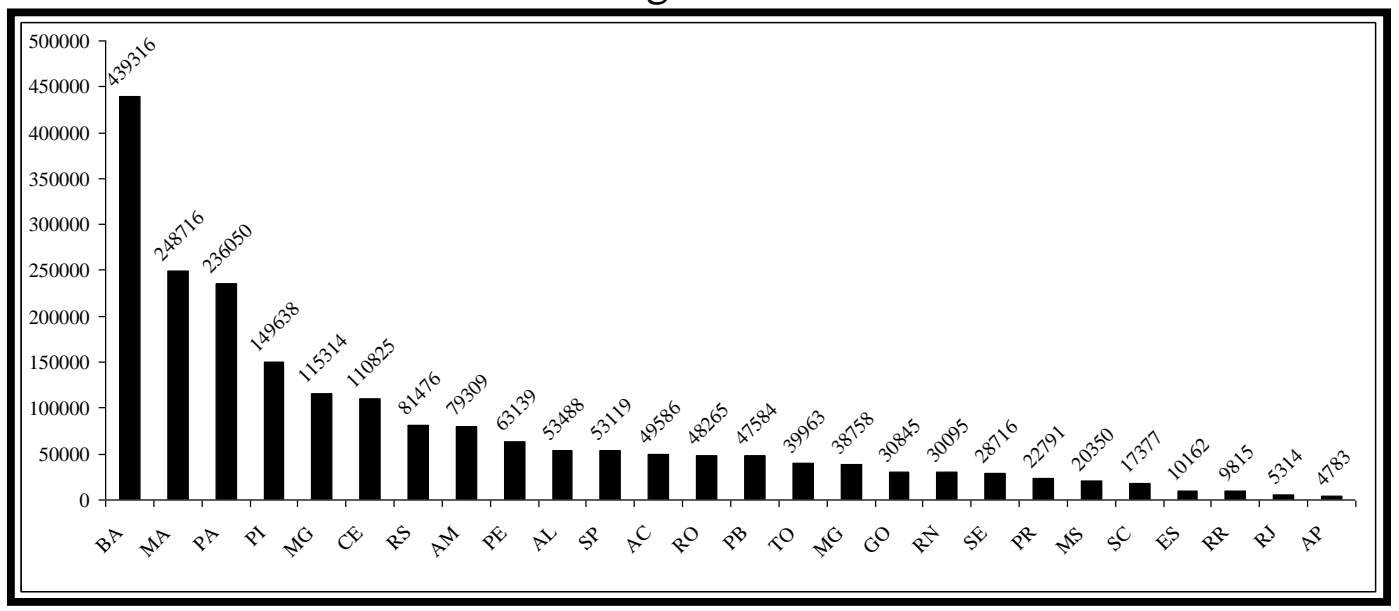

Fonte: IBGE/PNAD (2000).

A faixa de renda das famílias sem o fornecimento de energia elétrica é apresentada a seguir.

Tabela 2. Domicílios particulares permanentes, por classes de rendimento mensal domiciliar rural, e situação do domicílio e iluminação elétrica (mil unidades)

\begin{tabular}{|c|c|c|c|c|c|c|c|c|c|}
\hline $\begin{array}{c}\text { Rendimentos } \\
\text { (salário mínimo) }\end{array}$ & Até 1 & $>1 \mathrm{e}<2$ & $>2 \mathrm{e}<3$ & $>3 \mathrm{e}<5$ & $\begin{array}{c}>5 \mathrm{e} \\
<10\end{array}$ & $\begin{array}{c}>10 \mathrm{e} \\
<20\end{array}$ & $>20$ & SR & SD \\
\hline Domicílios & 637 & 483 & 214 & 112 & 37 & 6 & 3 & 26 & 51 \\
\hline$\%(1)$ & 40.7 & 30.78 & 13.63 & 7.13 & 2.35 & 0.38 & 0.19 & 1.65 & 3.25 \\
\hline
\end{tabular}

Fonte: IBGE, 2002. Até 2003 exclusive a população da área rural de Rondônia, Acre, Roraima, Amazonas, Pará, Amapá. (1) valores percentuais elaborados pelos autores. SR (sem rendimento). SD (sem declaração).

A lei $n^{\circ} 10.438 / 2002$ dispôs sobre a expansão da oferta de energia elétrica emergencial e a universalização do serviço de energia elétrica no território nacional e definiu que todos tem o direito a este serviço e o poder público é o responsável pelo atendimento. A resolução $n^{\circ} 223$ da Agência Nacional de Energia ElétricaANEEL (2003) define que a Concessionária é a responsável pelo atendimento do pedido de ligação para cada unidade consumidora, e sem ônus para o solicitante. A Concessionária submeterá à ANEEL o Plano de Universalização de Energia Elétrica da sua área de atuação. Ao não apresentar o Plano, a Concessionária assume a responsabilidade de atender toda a sua área de concessão.

$O$ decreto $n^{\circ} 4.873 / 2.003$ instituiu o Programa Nacional de Acesso e Uso da Energia Elétrica - Luz Para Todos (PLPT). A universalização e o PLPT definem a não 
decorrente o atendimento das expectativas dos usuários.

Quando a prestação do serviço ocorrer sucessivamente, dia após dia, sem interrupções no fornecimento ou sofrendo interrupções aceitáveis para os indicadores de continuidade coletivos, a satisfação do usuário aumentará, e um dos seus resultados poderá ser a ampliação da demanda decorrente ${ }^{2}$.

A demanda decorrente é identificada quando a finalização do PLPT é postergada pela presença de famílias excluídas do planejamento inicial do Programa. O objetivo inicial do PLPT definiu, até o ano 2008, o atendimento das famílias e a ampliação da rede de distribuição até os domicílios (MME, 2011). Posteriormente, $\mathrm{o}$ decreto $\mathrm{n}^{0}$ 6.442/2008 prorrogou $\mathrm{a}$ universalização para o ano 2010, e isto pela identificação da primeira demanda decorrente. Em seguida, o decreto $\mathrm{n}^{\circ}$ 7.324/2010 estendeu O PLPT até 31/12/2011, desta vez para a efetivação das conexões já contratadas ou a serem contratadas até 30/10/2010. Uma nova prorrogação ocorreu com o decreto $n^{\circ}$ 7.520/2011, desta vez para atender à demanda decorrente identificada pelas Distribuidoras de energia elétrica, e o decreto $\mathrm{n}^{\circ}$ 8.387/2014 altera o decreto anterior ao instituir a finalização do PLPT no ano 2.18. A implementação do PLPT, sem considerar a demanda decorrente, significa a defesa da expansão parcial e excludente.

Dados do Ministério de Minas e Energia-MME mostram que o PLPT “já chegou para 3.323.683 famílias, cerca de 15,9 milhões de moradores rurais de todo o país" (MME, 2016). A quantidade de famílias e pessoas atendidas pelo Programa é superior ao estabelecido incialmente, portanto, ao utilizar o quantitativo de unidades residenciais atualmente atendidas e subtrair pelo quantitativo inicial de unidades residenciais excluídas do acesso, o resultado é a demanda decorrente de 1.288.889 famílias atendidas pelo PLPT.

Ao atender à demanda decorrente, o custo do PLPT é ampliado. O orçamento disponibilizado inicialmente - aqueles R\$19 bilhões - foi ampliado para “R\$22,7 bilhões" (MME, 2016) para atender à demanda decorrente.

Permanecem no território brasileiro unidades domiciliares não atendidas pelo serviço de eletricidade. O governo federal aponta o deficit de 207.000 famílias sem o acesso à energia elétrica, 30.000 localizadas em regiões isoladas (MME, 2016). As regiões isoladas, como a Norte e os bairros rurais em áreas de preservação ambiental, as extensões simplificadas com postes, cabos, fios e transformadores são mais complexas porque requerem o corte e a derrubada de florestas, ações proibidas em determinados territórios, e a geração descentralizada. A particularidade ambiental demanda planejamento que envolve as questões legais, e a geração
2 A ANEEL exige que as Concessionárias mantenham padrão de continuidade e, para tal, edita limites para os indicadores coletivos de continuidade. DEC (Duração Equivalente de Interrupção por Unidade Consumidora), FEC (Frequência de Equivalente de Interrupção por Unidade Consumidora). Os indicadores de continuidade individuais são: DIC (Duração de Interrupção Individual por Unidade Consumidora), FIC (Frequência de Interrupção Individual por Unidade Consumidora), DMIC

(Duração Máxima de Interrupção Contínua por Unidade Consumidora ou Ponto de Conexão), DICRI

(Duração da Interrupção Individual Ocorrida em dia Crítico por Unidade Consumidora ou Ponto de Conexão). 
descentralizada requer atenção detalhada com os usuários e o processo correspondente à manutenção dos equipamentos.

\subsection{Multissetorialidades}

As multissetorialidades estabelecem correlações com as politicas de desenvolvimento territorial, os aspectos sociais, culturais e econômicos que podem integrar as demandas pela eletrificação rural. As ações multissetoriais são os financiamentos e créditos para assegurar o "incremento da produção agrícola, proporcionar o crescimento da demanda por energia elétrica, aumentar a renda e a inclusão social da população beneficiada" (MME, 2010) e estender o alcance das políticas públicas para este contingente populacional.

No conjunto das atividades multissetoriais, estão os Centros Comunitários de Produção-CCP, orientados para conferir apoios à aquisição de equipamentos produtivos e incentivar a geração de renda local.

Os Centros Comunitários de Produção são projetos de responsabilidade social complementares ao Programa Luz para Todos, em que a Eletrobras estabelece parcerias com associações ou cooperativas de pequenos agricultores, agências de extensão rural e governos locais para a implantação de pequenas agroindústrias com equipamentos elétricos para o beneficiamento de atividades econômicas rurais. Os CCPs promovem o uso produtivo e eficiente da energia elétrica e contribuem para a geração de trabalho e renda nas comunidades (ELETROBRAS, 2017).

Foram construídos com recursos do MME/PLPT e das comunidades beneficiadas mais de 650 CCPs (IICA, 2011, p. 78). Na Região Sudeste e no Estado de Goiás, áreas de atuação de FURNAS S.A., os CCPs construídos estão orientados para a criação de viveiros de mudas, produção de hortaliças, tanques para criação de peixes e de beneficiamento de leite, atelier de costura, máquinas de arroz e secadores de café (FURNAS, 2017); e nas áreas de atuação da Eletrosul, Região Sul e Mato Grosso do Sul, os CCPs desenvolvem panificação, resfriamento do leite, beneficiamento de mel, cerâmica, produção de bolsas e sacolas ecológicas, tecelagem, fábrica de erva-mate (ELETROSUL, 2011).

Não está descartada a existência de infraestruturas para geração de renda concebida com recursos familiares próprios ou com recursos provenientes de instituições financeiras. É o caso de desenvolver trabalho empírico, ir ao campo, visitar propriedades rurais, e prospectar informações nas propriedades beneficiadas pela eletrificação rural, identificar as mudanças ocorridas, conhecer as novas demandas das famílias atendidas pelo acesso à eletricidade, e traçar cenários futuros sobre as políticas públicas de desenvolvimento rural.

A organização de programas sociais e culturais está no conjunto multissetorialidade. O “Telecentro Comunitário" (parceria entre o PLPT e o projeto Eletrobras digital) consiste em salas de informática organizadas para a inclusão digital das famílias beneficiadas pelo PLPT. O programa "Bibliotecas Rurais - Arca das letras" é inciativa do Ministério de Desenvolvimento Agrário para aproximar a população rural dos livros, e faz parte da função social do PLPT. O programa "Rádios Comunitárias" é um dos canais para a comunicação, e de estimulo das 
manifestações culturais, artísticas, folclóricas, e de preservação dos valores e das tradições.

O propósito fim da multissetorialidade é estender as ações do poder público até os bairros rurais e não ficar circunscrita apenas ao fornecimento de energia elétrica. O desenvolvimento rural requer políticas públicas orientadas para a geração de renda, mas também para integrar os elementos socioculturais e de solidariedade, o folclore, o pertencimento, a identificação, o socioambientalismo, os quais, não necessariamente, estão relacionados às atividades econômicas.

\subsection{Alguns resultados do Programa Luz Para Todos}

Em muitos aspectos, os resultados do PLPT são positivos. O atendimento da demanda existente e da demanda decorrente caracteriza a universalização do PLPT.

O MME divulgou pesquisa sobre a satisfação das famílias atendidas pelo PLPT. Dentre os resultados encontrados, está a constatação de melhorias nas condições e oportunidades de estudos (inclusive noturno), trabalho e saúde no meio rural, o aumento na renda familiar para 35,6\% dos interlocutores e a demonstração de que a chegada da energia elétrica promove o desenvolvimento econômico e social das comunidades (MME, 2010), e estão melhores a qualidade de vida e as condições de moradia para $89,3 \%$ dos entrevistados, sendo que $86 \%$ deles identifica a melhor qualidade de vida após o acesso à energia elétrica.

Esta mesma pesquisa mostra a dinâmica do PLPT para a chamada indústria de equipamentos linha branca. Os indicadores mostram que as famílias beneficiadas compraram televisores, geladeiras, ventiladores, aparelhos de som, freezer, liquidificadores (MME, 2010). É uma nova dinâmica econômica que contrasta com as ideológicas concepções que identificam o proletariado rural como incapaz de utilizar energia elétrica.

A pesquisa do MME (2014) estima que 4,9\% das famílias beneficiadas retornaram ou passaram a morar no Bairro Rural após o acesso à energia elétrica. No trabalho de Motta, Silveira e Falek (2010) está o indicador de 23,4\% dos interlocutores beneficiados pelo PLPT relatando o interesse pela migração quando é considerada a inexistência do acesso universal à energia elétrica. São concepções que definitivamente identificam a importância e o uso da energia elétrica para o trabalho, lazer, comunicação, estudos, para reduzir o êxodo rural, extensão da vida noturna.

A prospecção de informações nos territórios beneficiados pelo PLPT permanece necessária. A implementação do PLPT produz movimentos e dinâmicas não restritas à universalização e, por si só, necessitam de identificação para o planejamento das políticas públicas.

\section{Considerações finais}

O histórico da expansão da rede de distribuição de energia elétrica nos bairros rurais envolveu muitos e diferentes projetos de eletrificação rural, privados e públicos em implementação simultânea e utilizando como o principal critério para as expansões a cobrança das instalações. A cobrança definia que o acesso à eletricidade dependia da capacidade de pagamento da família interessada. Embora 
a cobrança tenha atuado como um elemento impeditivo para a universalização, as experiências brasileiras com eletrificação rural produziram aprendizados que passaram a compor programas posteriores.

As experiências com arranjos institucionais entre o poder público (governos federal, estadual, municipal), empresas concessionárias de energia elétrica, bancos de financiamento e cooperativas rurais contribuíram com a evolução da eletrificação rural no Brasil. Além disso, os programas de eletrificação rural PROLUZ I, PROLUZ II, Luz Terra - sofreram interferência política representada pelo rompimento do paradigma da eletrificação rural pautada em preciosismos, descoladas das necessidades e condições de pagamento da população rural, e contribuíram para o salto qualitativo que é a eletrificação rural de baixo custo. Há, ainda, a interferência provocada pela articulação entre os agentes econômicos (indústria brasileira de energia elétrica) e o agente político (governo federal) que originou o Acordo Geral do setor elétrico para recomposição do mercado de eletricidade em crise e, somente enquanto moeda de troca, as Concessionárias concordaram em cumprir a lei $n^{\circ} 10.438 / 2002$ de universalização do atendimento.

Em retrospectiva, o conjunto dos programas de eletrificação rural brasileiros evidenciaram os limites econômicos do proletariado rural interessado no serviço e identificaram como prognóstico o acesso gratuito.

A política de universalização e o PLPT romperam com a concepção que determinava a compra da infraestrutura para a prestação do serviço de energia elétrica rural, e finalizaram com a estratificação que definia as famílias que podiam e aquelas que não podiam comprar e acessar o fornecimento. Ainda, as ações multissetoriais e programas sociais integrados ao PLPT contribuíram com a oferta de políticas de desenvolvimento rural, e com a presença de políticas sociais junto aos bairros rurais e famílias beneficiadas pela universalização do acesso e uso da energia elétrica. Finalmente, o acesso ao fornecimento de eletricidade produziu, produz e produzirá modificações nas dinâmicas sociais, ambientais, culturais e econômicas, características que determinam a necessária prospecção de informações nos territórios beneficiados pelo PLPT.

\section{REFERÊNCIAS}

AGÊNCIA NACIONAL DE ENERGIA ELÉTRICA. Resolução $n^{\circ}$ 223. Diário Oficial da União [República Federativa do Brasil], Brasília, DF, 27. 10. 2.004.

\section{BETIOL, G. B. Programa Luz Para Todos em São Paulo: Planos de obras confrontados com a prática das distribuidoras, visando redução de custos com a eletrificação rural. Mestrado em Energia, Universidade de São Paulo, São Paulo, 2.005 .}

BRASIL. Decreto Federal n 4.873. Institui o Programa Nacional de Acesso e Uso da Energia Elétrica “Luz Para Todos" e dá outras providências. Diário Oficial da União [República Federativa do Brasil], Brasília, DF, 12 de nov. 2003. 
BRASIL. Decreto Federal $n^{\circ} 6.442$. Da nova redação ao artigo $n^{\circ} 1$ do decreto $n^{\circ}$ 4.873, de 11 nov. 2003, [...] para prorrogar o prazo ali referido. Diário Oficial da União [República Federativa do Brasil], Brasília, DF, 28 abr. 2008.

BRASIL. Decreto Federal n 7.324. Dá nova redação ao art. $1^{\circ}$ do Decreto no 4.873, de 11 de novembro de 2003, que institui o Programa Nacional de Universalização do Acesso e Uso da Energia Elétrica. Diário Oficial da União [República Federativa do Brasil], Brasília, DF, 6 ago. 2010.

BRASIL. Decreto Federal n 7.520. Prorrogação do Programa Luz Para Todos, até o ano 2014, em todo o país. Diário Oficial da União [República Federativa do Brasil], Brasília, DF, 11 jul. 2011.

BRASIL. Decreto Federal n 8.387. Altera o Decreto n- 7.520, 8 jul. 2011, que institui o Programa Nacional de Universalização do Acesso e Uso da Energia Elétrica. Diário Oficial da União [República Federativa do Brasil], Brasília, DF, 31 dez. 2014.

BRASIL. Decreto Federal $n^{\circ}$ 41.019. Obrigatoriedade das concessionárias fornecerem energia elétrica regional. Diário Oficial da União [República Federativa do Brasil], Brasília, DF, 12. mar. 1957.

BRASIL. Decreto Federal n 62.655. Regulamenta a execução da eletrificação rural mediante autorização para uso privativo. Diário Oficial da União [República Federativa do Brasil], Brasília, DF, 3 mai. 1968a.

BRASIL. Decreto Federal $n^{\circ}$ 62.724. Estabelece normas gerais de tarifação para as empresas concessionárias de serviços públicos de energia elétrica. Diário Oficial da União [República Federativa do Brasil], Brasília, DF, 20 mai. 1968b

BRASIL. Decreto Federal n 67.052. Institui o Fundo de Eletrificação Rural e dá outras providências. Diário Oficial da União [República Federativa do Brasil], Brasília, DF, 14 ago. 1970.

BRASIL. Decreto Presidencial sem número. Institui o Programa Nacional de Eletrificação Rural Luz no Campo e dá outras providências. Diário Oficial da União [República Federativa do Brasil], Brasília, DF, 3. dez. 1999.

BRASIL. Lei federal $n^{\circ} 8$. Cria o Serviço de Fomento de eletrificação rural e dá outras providências. Diário Oficial da União [República Federativa do Brasil], Brasília, 1948.

BRASIL. Lei Federal n ${ }^{\circ}$ 4.504. Dispõe sobre o Estatuto da terra. Diário Oficial da União [República Federativa do Brasil], Brasília, DF, 31 nov. 1964.

BRASIL. Lei Federal n॰ 10.438. Dispõe sobre a expansão da oferta de energia elétrica emergencial, recomposição tarifária extraordinária, cria o Proinfa e a CDE e dispõe sobre a universalização do serviço público de energia elétrica [...]. Diário Oficial da União [República Federativa do Brasil], Brasília, DF, 29 abr. 2002. 
CAMARGO, E.; RIBEIRO, F. S.; GUERRA, S. M. G. O Programa Luz Para Todos: metas e resultados. Revista Espaço e Energia, n 9, p. 21 - 24, 2008.

CARMO, J. Planejamento e operação de políticas públicas de eletrificação rural no estado de São Paulo. Mestrado em Energia, Universidade de São Paulo, São Paulo, 2005 .

CORREIA, J. S. S.; PEREIRA, O. S.; BARRETO, E. J. F.; MOUSINHO, T.; FONTOURA, P. F. Perspectiva para a universalização da eletrificação no estado da Bahia. Bahia Análise \& Dados, $n^{\circ}$ 4, v. 11, 2002.

ELETROBRAS. Relatório anual da Eletrobras. 2002. Disponível em: <https://www.eletrobras.com/elb/main.asp?Team=\%7B50EA5A6D-199A-47EF-91043DA446A793B1\%7D>. Acesso em: 5 abr 2017.

ELETROBRAS. Responsabilidade social. 2017. Disponível em: <http://www.eletrobras.com/elb/data/Pages/LUMISAB5757A8PTBRIE.htm>. Acesso em: 25 abr. 2017.

ELETROSUL. Eletrosul promove a $1^{\mathrm{a}}$ Feira do Programa Luz Para Todos. 2011. Disponível em: <http://www.eletrosul.gov.br/sala-de-imprensa/noticias/eletrosulpromove-a-1-feira-do-programa-luz-para-todos>. Acesso em: abr. 2017.

FURNAS CENTRAIS ELÉTRICAS. Ações integradas. 2.017. Disponível em: <http://www1.furnas.com.br/luzparatodos/CCP.htm>. Acesso: 3 mar. 2017.

INSTITUTO BRASILEIRO DE GEOGRAFIA E ESTATÍSTICA. Aspectos socioeconômicos. 2002. Disponível em:

<http://www2.aneel.gov.br/aplicacoes/atlas/aspectos_socioeconomicos/11_2_1.htm> . Acesso em: Acesso em: 10. abr. 2017.

INSTITUTO BRASILEIRO DE GEOGRAFIA E ESTATISTICA. 2.000. Estimativa de déficit de ligações rurais por estado da Federação no início do PLPT. Disponível em: [www.ibge.gov.br]. Acesso em jan. 2017.

INSTITUTO INTERAMERICANO DE COOPERAÇÃO PARA AGRICULTURA. Universalização do acesso e uso da energia elétrica no meio rural brasileiro: lições do programa Luz para Todos. Brasil: IICA, 2011.

JERONYMO, A. C. J. Expansao do estado capitalista no contexto da politica de universalização do acesso e uso da energia elétrica. Doutorado em Energia, Universidade Federal do ABC, Santo André, 2012.

MARQUES, R. M. B. S. Universalização do atendimento: o paradoxo da exclusão dos inadimplentes dos programas de eletrificação rural anteriores. Mestrado em Energia, Universidade de São Paulo, São Paulo, 2005. 
MASSOCHIN, A. O Programa de Eletrificação Rural Clic Rural seus efeitos e implicações na região Oeste do Paraná 20 anos depois. Mestrado em Engenharia, Universidade Estadual do Oeste do Paraná, Cascavel, 2006.

MERCEDES, S. S. P.; RICO, J. A. P.; POZZO, L. Y. Uma revisão histórica do planejamento do setor elétrico brasileiro. Revista USP, nº 104, p. 13-36, 2015.

MINISTÉRIO DE MINAS E ENERGIA. Programa Luz Para Todos: um marco histórico, 10 milhões de brasileiros saíram da escuridão. 2010. Disponível em: <https://www.mme.gov.br/luzparatodos/downloads/Livro_LPT_portugues.pdf>. Acesso: 20 mai. 2016.

MINISTÉRIO DE MINAS E ENERGIA. Programa Nacional de Universalização do acesso e uso da energia elétrica: manual de operacionalização do Programa Luz Para Todos, Brasília, 2011.

MINISTÉRIO DE MINAS E ENERGIA. 10 anos, 15 milhões de pessoas atendidas: os impactos do Programa Luz Para Todos. 2014. Disponível em:

<http://luzparatodos.mdapesquisa.com.br/>. Acesso em jan. 2015.

MINISTÉRIO DE MINAS E ENERGIA. O Programa. 2.016. Disponível em: https://www.mme.gov.br/luzparatodos/Asp/o_programa.asp. Acesso em: jan. 2017.

MOTTA, J. A.; SILVEIRA, M. T.; FALEK, A. C. Eletrificação rural e o PLPT: uma avaliação da percepção dos beneficiários. In.: MORAES, M. P.; COSTA, M. A. (Org.). Infraestrutura social e urbana no Brasil: subsídios para uma agenda de pesquisa e formulação de políticas públicas. Brasília: IPEA, 2010.

OLIVEIRA, A. Energia e desenvolvimento sustentável. Rio de Janeiro: Instituto de Economia, Universidade do Rio de Janeiro, 1998.

OLIVEIRA, L. C. Perspectivas para eletrificação rural no novo cenário econômico institucional do setor elétrico. Mestrado em Planejamento Energético, Universidade Federal do Rio de Janeiro, Rio de Janeiro, 2001.

PAGLIARDI, O.; SOBRINHO, A.; JULIANI, J. A.; BERNARDI, W. Os principais programas de investimento na eletrificação rural paulista e seus benefícios. In.: $3^{\circ}$ Encontro de Energia no Meio Rural, Campinas, 2003.

PELEGRINI, M. A. Política de eletrificação rural em São Paulo (1995 - 1997). Mestrado em Engenharia, Universidade de São Paulo, São Paulo, 1998.

PEREIRA, M. G. Políticas públicas de eletrificação rural na superação da pobreza energética brasileira: estudo de caso da bacia do rio Acre, Amazônia. Tese em Planejamento Energético, Universidade Federal do Rio de Janeiro, Rio de Janeiro, 2009. 
RIBEIRO, F. S. Eletrificação rural de baixo custo. Tese em Engenharia, Universidade de São Paulo, São Paulo, 1993.

RIBEIRO, F. S. Luz para Todos ou Universalização do Atendimento: como garantir a continuidade da inclusão social. In.: $7^{\circ}$ Congresso Internacional sobre geração distribuída e energia no meio rural, Fortaleza, 2008.

RIBEIRO, F. S.; PAZZINI, L. H. A.; PELEGRINI, M. A.; KURAHASI, L. F.; GALVÃO, L. C. R. Programa "Luz da Terra" - modelo de eletrificação rural participativo. $3^{\circ}$ Encontro Energia no meio rural, Campinas, 2003.

RIBEIRO, F. S.; SANTOS, J. F. M. S. Política de eletrificação rural: superando dilemas institucionais. Revista do BNDES, v. 1, n² 2, p. 131 - 152, 1994.

ROSA, F. L. O; RIBEIRO, F. S; MELLO, R. S. Programa de eletrificação rural simplificada para pequenas propriedades agrícolas do Rio Grande do Sul/PROLUZ Brasil: avaliação preliminar de resultados. In.: XIV Conferencia Latinoamerica de Electrificación Rural, Uruguay, Punta del Leste, 1993.

SÃO PAULO. Decreto n ${ }^{\circ}$ 41.187. Institui o Programa de Eletrificação Rural Luz da Terra e a Comissão de Eletrificação Rural do Estado de São Paulo. Diário Oficial do Estado de São Paulo, São Paulo, 25 set. 1996.

SILVA, E. R. Eletrificação rural e o processo de modernização da agricultura brasileira. Tese em Economia, Universidade Federal de Minas Gerais, Belo Horizonte, 1996.

SOUZA, C. R. G.; ANJOS, F. S. Impacto dos programas de eletrificação rural em comunidades de Arroio Grande, RS. Revista Extensão Rural, jan./dez., p. 37 - 63, 2007.

STRAZZI, P. E. Desenvolvimento social e programas de eletrificação de não atendidos. Tese em Energia, Universidade de São Paulo, São Paulo, 2009.

TRIBUNAL DE CONTAS DA UNIÃO. Relatório do ministro relator. 2.003. Disponível em: <http://portal.tcu.gov.br/lumis/portal/file/fileDownload.jsp?inline= 1\&fileld=8A8182A14D92792C014D92848CF5479B >. Acesso em: mai. 2017.

Alexandre Cosme José Jeronymo. Doutor em Energia, Mestre em Energia (USP) e Cientista Social (UNESP). alexandrecjj@gmail.com

Sinclair Mallet-Guy Guerra. Livre docente (Unicamp), Doutor em Economia da Energia (Université Paris III), Mestre em Economia de Empresas (FGV, Graduação em Economia (Universidade de Marília).sguerra@gmail.com 